\title{
Biochar From Sugarcane Waste In Polymer Matrix Composite
}

\author{
R. SundaraKannan, V. Arumugaprabu, G. Poomari Muthukumar, S.Vigneshwaran, S.R. \\ Deepan saravana kumar, R.Muneesh raj.
}

\begin{abstract}
The present work focuses on development of new type composite using bio char as reinforcement. The bio char is derived from sugarcane waste when undergo pyrolysis process. Because of the growing demand for waste utilization development of bio char from such wastes proves to be a potential one for various applications. In this study focuses bio char reinforced saturated polyester resin for composite fabrication. The composites are prepared by solution dispersion method. Bio char of different weight percentages such as 5, 10 and $15 \%$ were reinforced polyester matrix for taken this study. The prepared specimens are subjected to tensile strength, flexural strength, hardness and impact strength.
\end{abstract}

Keywords: Bio char, Polyester matrix, Solution dispersion method, Tensile strength, Flexural strength, Impact strength and Hardness.

\section{INTRODUCTION}

$\mathrm{R}$ Recently natural available substances can be used as reinforcement in composites. Current trends in composites these composites to play a vital votes in future environmental problems. By using the application of bio char which it reduce the offsite pollution. Here can be a effectively utilized for load heavy application, study on the interaction of the biochar with polymers and evaluation on the composite properties. Bio char obtained by the pyrolysis process and it is used as particulate reinforcement in unsaturated polymer matrix. These particulated biochar filed composites several work has been reported. For disposal of agricultural waste from this method was reduced environment pollution. Lee, $\mathrm{Y}$ et al studied that comparison of characteristics of biochar produced by slow pyrolysis at $500{ }^{\circ} \mathrm{C}$ for agricultural

Revised Manuscript Received on December 30, 2019.

* Correspondence Author

R. SundaraKannan, Department of Mechanical Engineering, Kalasalingam Academy of Research and Education, Krishnankovil -626 126. Email: gpoomari@klu.ac.in.

V. Arumugaprabu, Department of Mechanical Engineering, Kalasalingam Academy of Research and Education, Krishnankovil -626 126. Email: gpoomari@klu.ac.in.

G. Poomari Muthukumar, Department of Mechanical Engineering, Kalasalingam Academy of Research and Education, Krishnankovil -626 126. Email: gpoomari@klu.ac.in.

S.Vigneshwaran, Department of Mechanical Engineering, Kalasalingam Academy of Research and Education, Krishnankovil -626 126. Email: gpoomari@klu.ac.in.

S.R. Deepan saravana kumar, Department of Mechanical Engineering, Kalasalingam Academy of Research and Education, Krishnankovil -626 126. Email: gpoomari@klu.ac.in.

R.Muneesh raj. Department of Mechanical Engineering, Kalasalingam Academy of Research and Education, Krishnankovil -626 126. Email: gpoomari@klu.ac.in. residues. The biochar characterization, elemental composition and $\mathrm{pH}$ of biochar were also compared [1]. Richard et al investigated that biochar obtained by the pyrolysis of rice husk as a particulate reinforcement in unsaturated polyester matrix. Different size of particle loading polyester composites and their mechanical and dielectric properties were analysed [2]. Amir nourbakhsh et al fabricated the wood flour reinforced polypropylene composites. Various particle sizes were loading polypropylene matrix composites and reported that smaller ratio particles were increased mechanical properties [3]. Siddhartha et al presented titania filler reinforced epoxy composites inclusion of different weight percentages. Various sliding wear parameters were noted and $20 \%$ filled composites found that optimum wear rate of the composites [4]. Shankundala ojha, et al compared that wood apple and coconut shell particle reinforced epoxy matrix composites. The mechanical and erosion behaviour of prepared composites were analysed, superior strength of properties occurred on $15 \%$ particle reinforced composites. Compare with coconut shell composites wood apple filled composites reached the maximum strength of mechanical strength and low erosion rate of composites [5]. Aamer Khan et al investigated on mechanical and electrical properties on low cost filler reinforced epoxy composites. Biochar and carbon nanotubes were reinforced epoxy matrix at various weight percentages. Biochar filled composites reached that better mechanical properties compare with other filler. But the electrical properties were maximum reached as carbon nanotubes filled composites [6]. Imran Oral investigated on comparison of two biochar reinforced epoxy matrix composites. China Poplar Char and Pine Cone Char were loading at 10, 20 and $30 \%$ wt in epoxy matix composites. Overall compared between the mechanical properties china polar biochar reinforced composites $30 \%$ wt is suitable composites [7]. Steven C. Peterson studied that three type of biochar prepared from corn starch, flour and stover and it is filled with rubber matrix composites. Three biochar properties were compared and the mechanical behaviour was increased by corn starch filled composites [8]. Qingfa Zhang et al prepared the rice husk biochar and wood flour reinforced the high density polyethylene matrix composites. The mechanical behaviour was observed from that composites initially tend to rised. 


\section{Biochar From Sugarcane Waste In Polymer Matrix Composite}

According to that more addition filler droped the mechanical properties. Maxium mechanical properties was observed from ricehusk biochar reinforced HDPE composites [9]. This objective of this study to prepare the cashew char reinforced polyester composites at various loading percentage. Mechanical behaviour of tensile, flexural, impact and hardness properties was analysed. The maximum mechanical properties reached on $10 \%$ biochar filled polyester composites.

\section{MATERIALS AND METHODS}

The raw materials were purchased the material in Madurai. the used material was empty Tin box , cashew nut shell, gloves, glass mould, clips, The bio char we were used in sugarcane waste was used to fabricate bio char reinforced polyester composites. The sugarcane waste is burned in the furnace in $500^{\circ} \mathrm{c}$ for 1 hours. Further the biochar conduct ball milling for 5 hours the weight ratio is $1: 10$ ball weight. The two glass mould was taken and applied the wax in the glass mould the surface of the glass mould in $3 \mathrm{~mm}$ thickness.

The polyester resin takes in the plastic beaker and mixed with biochar. After that the acceleration and catalyst added by using of curing composite plates for 5 hours. Finally remove the glass mould and get the bio char filled composite plates. The prepared composite plates conduct on mechanical properties of tensile test, flexural test Impact test and hardness test.

\section{RESULTS AND DISCUSSION}

\section{A. Tensile strength}

Different percentage of sugarcane char fabricated composites tensile strength was shown in figure 1. The biochar filled composites tensile strength values significantly improvement of the tensile strength. Initially $5 \%$ filled composites revealed that improvement $11 \%$ tensile strength. Interlocking properties with biochar and polyester resin was clearly observed from this graph. Increasing of biochar $10 \%$ filled composites reached that maximum tensile strength and $14 \%$ improved. Furthermore inclusion of filler to decreased the tensile strength of biochar composites.

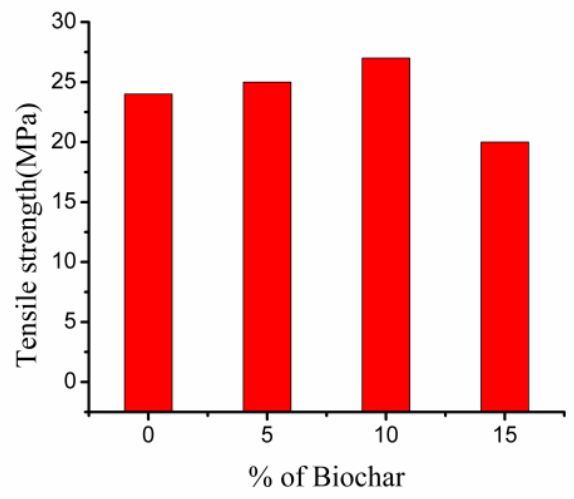

Fig. 1 Tensile strength of biochar filled polyester composites

\section{B. Flexural strength}

$\mathrm{G}$ The Flexural strength of biochar reinforced polymer composite results plot a graph as shown in figure 2. Different weight percentage of biochar addition of polyester matrix and their results significantly improved. The flexural strength was performed as three different percentages and 5\% reinforcement flexural strength was slightly improved. The bio char particles were dispersion with matrix to increases of flexural strength. Moreover, to increase the filler content, to be also improvement of flexural strength was noted. To identify that maximum flexural strength was occurs on $15 \%$ filled composite. It was clearly to increased the flexural strength that may caused by the bio char powder to form as a good inter locking between the matrix.

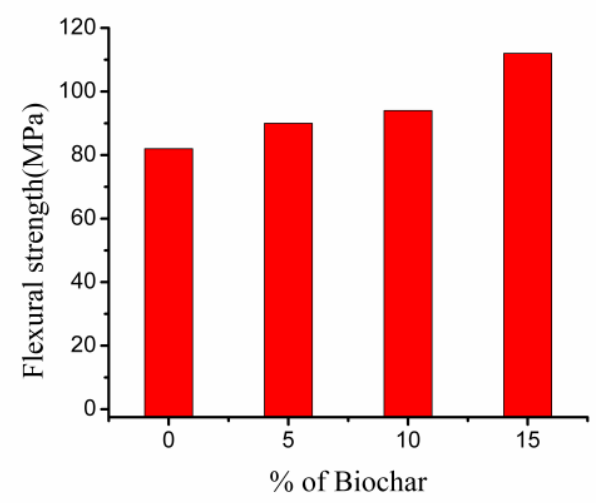

Fig. 2 Flexural strength of biochar filled polyester composites

\section{Impact strength}

Sugarcane biochar reinforced polyester composites fabricated and their impact strength results as shown in figure 3. The results expressed that inclusion bio char filled composites to absorption of impact energy and increased their strength compared with $5 \%$ filled composites to improvement of their impact energy on $10 \%$ filled composites. It was noted that to dispersion of bio char particles are very good. Moreover addition on $10 \%$ to decreased the Impact strength. It can be notified that of particle from as cluster or group and it lead to week of the composites.

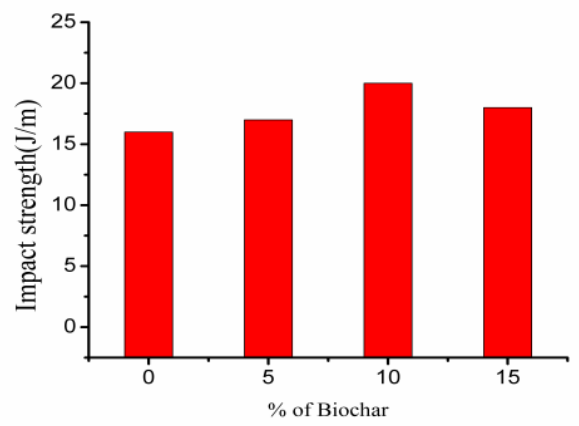

Fig. 3 Impact strength of biochar filled polyester composites

\section{Hardness strength}

Hardness average values are shown in figure 4 . In each biochar plate 10 different readings are taken from the readings find the average values of revolved the toughness of the material. Neat polyester compared with biochar filled polymer composites. 
It shows that $10 \%$ of sugarcane biochar composite reaches the maximum hardness values. Incorporation of biochar upto $10 \%$ filled polyester composite plates has significantly increasing the hardness values. Where $15 \%$ filled composites revealed that the decreases of the hardness value Due to cluster formation of biochar.

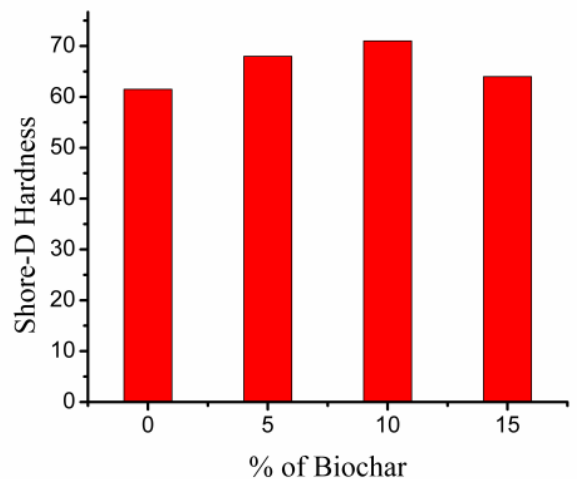

Fig. 4 Hardness of biochar filled polyester composites

\section{CONCLUSION}

By observing the composite which is made up of bio char reinforce with polyester matrix when it is subjected to tensile, impact hardness, flexural can be drawn us follows.

- Composite is manufacturing by using glass moulding method, several components are made with different proportion of bio char. $10 \%$ of sugarcane biochar in the composite had high hardness number due to the reinforcement of bio char powder.

- Impact test in the composite showed that addition of bio char powder improved impact test significantly at $10 \%$. Furthermore properties of component of tensile strength have improved at $10 \%$ of milled bio char.

- Increasing percentage of bio char over $10 \%$ has rapidly decreased the properties of composite such as tensile, impact, hardness.

- By conducting flexural test in the composites made by bio char reinforced polyester matrix has increased flexural strength. Flexural strength is increased gradually by increasing the percentage upto $10 \%$ of reinforcement.

\section{REFERENCES}

1. Y. Lee, J. Park, C. Ryu, K. S. Gang, W. Yang, Y. K. Park and S. Hyun, "Comparison of biochar properties from biomass residues produced by slow pyrolysis at 500 C,", Bioresource technology, 148, 2013, 196-201.

2. S. Richard, J. S. Rajadurai and V. Manikandan, "Influence of particle size and particle loading on mechanical and dielectric properties of biochar particulate-reinforced polymer nanocomposites," International Journal of Polymer Analysis and Characterization,21(6), 2016, 462-477.

3. A. Nourbakhsh, A. Karegarfard, A. Ashori and A. Nourbakhsh, "Effects of particle size and coupling agent concentration on mechanical properties of particulate-filled polymer composites," Journal of Thermoplastic Composite Materials, 23(2), 2010, 169-174.

4. A. Patnaik and A. D. Bhatt, "Mechanical and dry sliding wear characterization of epoxy-TiO2 particulate filled functionally graded composites materials using Taguchi design of experiment," Materials \& Design, 32(2), 2011, 615-627.

5. S. Ojha, G. Raghavendra and S. K. Acharya, "A comparative investigation of bio waste filler (wood apple-coconut) reinforced polymer composites," Polymer Composites, 35(1), 2014, 180-185.
6. A. Khan, P. Savi, S. Quaranta, M. Rovere, M. Giorcelli, A. Tagliaferro and C. Jia, "Low-cost carbon fillers to improve mechanical properties and conductivity of epoxy composites" Polymers, 9(12), 2017, 642.

7. I. Oral, "Determination of elastic constants of epoxy resin/biochar composites by ultrasonic pulse echo overlap method," Polymer Composites, 37(9), 2016, 2907-2915.

8. S. C. Peterson, "Evaluating corn starch and corn stover biochar as renewable filler in carboxylated styrene-butadiene rubber composites," Journal of Elastomers \& Plastics, 44(1), 2012, 43-54.

9. Q. Zhang, W. Yi, Z. Li, L. Wang and H. Cai, "Mechanical properties of rice husk biochar reinforced high density polyethylene composites," Polymers, 10(3), 2018, 286.

\section{AUTHORS PROFILE}

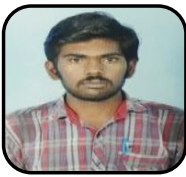

First Author R. Sundarakannan is a Research Scholar in the Department of Mechanical Engineering, School of Automotive and Mechanical Engineering,Kalasalingam Academy of Research Education, Krishnankoil, Tamilnadu, India. He graduated B. Tech in Mechanical Engineering in the year 2015, Graduated M.Tech in Engineering Design in the year 2017 both at Kalasalingam University, India. His area of research is polymer-based composites.

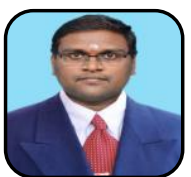

Second Author V. Arumugaprabu working as Associate Professor in the Department of Mechanical Engineering, School of Automotive and Mechanical Engineering, Kalasalingam Academy of Research and Education, Krishnankoil, Tamilnadu, India. He graduated B.E in Mechanical Engineering at AKCE in the year 2005, Graduated M.E in CAD/CAM at MepcoSchlenk Engg., college ,Graduated Ph.D in Composite Materials in the year 2014 at Kalasalingam, krishnanakoil. He has very vast research experience in the field of composite materials with nearly 35 publications in various reputed SCI Journals.

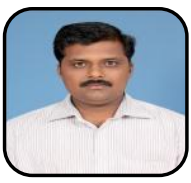

Third Author G.Poomari muthukar has working Assistant Professor Department of Mechanical Engineering, School of Automotive and Mechanical Engineering, Kalasalingam Academy of Research and Education, Krishnankoil, Tamilnadu, India. Also he has a working on industrial experience 5 years. 